\title{
Firearm related deaths: the impact of regulatory reform
}

\author{
J Ozanne-Smith, K Ashby, S Newstead, V Z Stathakis, A Clapperton
}

Injury Prevention 2004;10:280-286. doi: 10.1136/ip.2003.004150

See end of article for authors' affiliations .....................

Correspondence to: Professor Joan OzanneSmith, Monash University Accident Research Centre, Building 70, Monash University, Victoria 3800, Australia;

joan.ozanne-smith@ general.monash.edu.au

\begin{abstract}
Objectives: To examine trends in rates of firearm related deaths in Victoria, Australia, over 22 years in the context of legislative reform and describe and investigate impact measures to explain trends.

Design: Mortality data were extracted from vital statistics for 1979-2000. Data on firearm related deaths that were unintentional deaths, assaults, suicides, and of undetermined intent were analyzed. Rates were calculated with population data derived from estimates by the Australian Bureau of Statistics. A quasiexperimental design that used a Poisson regression model was adopted to compare relative rates of firearm related deaths for Victoria and the rest of Australia over three critical periods of legislative reform. The Wilcoxon signed ranks test was used to assess changes in the types of firearm related deaths before and after 1998.

Results: In Victoria, two periods of legislative reform related to firearms followed mass shooting events in 1988 and 1996. A national firearm amnesty and buyback scheme followed the latter. Victorian and Australian rates of firearm related deaths before reforms (1979-86) were steady. After initial Victorian reforms, a significant downward trend was seen for numbers of all firearm related deaths between 1988 and 1995 (17.3\% in Victoria compared with the rest of Australia, $p<0.0001)$. A further significant decline between 1997 and 2000 followed the later reforms. After the later all state legislation, similar strong declines occurred in the rest of Australia from 1997 (14.0\% reduction compared with Victoria, $p=0.0372$ ). Victorian reductions were observed in frequencies of firearm related suicides, assaults, and unintentional deaths before and after the 1988 reforms, but statistical significance was reached only for suicide.

Conclusion: Dramatic reductions in overall firearm related deaths and particularly suicides by firearms were achieved in the context of the implementation of strong regulatory reform.
\end{abstract}

$\mathrm{D}$ eaths and non-fatal injuries from firearms remain a major public health problem in many countries, including the United States, Mexico, South Africa, Columbia, Estonia, and Brazil. ${ }^{1}$ In the United States in 2000, 28663 firearm related deaths occurred (10.4 per 100000 population). ${ }^{2}$ In addition, in 1997, an estimated 64207 firearm related injuries were treated in American hospital emergency departments (24.0 per 100000 population; 95\% confidence interval 13.8 to 34.1 ), with about $40 \%$ of patients needing inpatient hospital care. ${ }^{3}$ American inpatient care costs for people with firearm related injuries in 1993 were reported as $\$ 4$ billion. ${ }^{4}$ Strong correlations have been reported between firearm ownership and firearm related suicide, homicide, assault, and unintentional deaths..$^{5-13}$

The American annual rate of firearm related deaths decreased by $2 \%$ from 10.6 per 100000 population in 1999 to 10.4 per 100000 in $2000 .^{2}$ Other Western industrialised nations also have shown reductions. Canadian rates of firearm related deaths are available for 1970-99 and show a decrease from a peak of 7.2 per 100000 population in 1977 and 1978 to a low of 3.3 per 100000 in 1998 and $1999 .{ }^{14}$ Rates of firearm related deaths in New Zealand over the 12 years from 1988 to 1999 decreased from 4.5 per 100000 in 1988 to 1.3 per 100000 in $1999 .{ }^{15}$ In Australia in 2000, the rate of firearm related deaths had declined to 1.8 per $100000-$ about $20 \%$ of the corresponding rate in the United States. Comparison of the trends and relatively low rate of firearm related deaths in Australia with those of other countries provide contrasts that may be of public health benefit internationally. Furthermore, comparisons of firearm ownership in 2000 showed that about 33\% of American households had firearms compared with $11 \%$ of Australian households. ${ }^{216}$

The relation between strengthening firearm control regulations and rates of firearm related deaths warrants further investigation. In Australia, regulation of firearms is under state jurisdiction, and variance over time between the strength of state laws provides a natural experiment.

\section{FIREARMS LEGISLATION IN AUSTRALIA}

In Victoria, two episodes of tightening of firearm laws followed mass shooting events. The first, in 1988, followed the 1987 Hoddle and Queen Street massacres and the combined deaths of 15 people. After these events, the federal government established a National Committee on Violence, whose recommended reforms included uniform national firearm laws. At a state premiers' conference in 1987, two states refused to adopt this national approach. Victoria tightened restrictions on semiautomatic longarms in 1988 but fell short of the recommended national uniform laws (fig 1$).{ }^{16}$

Uniform firearm laws finally were achieved nine years later in the aftermath of the 1996 Port Arthur massacre in Tasmania (35 deaths). In May 1996, the Australian Police Ministers' Council agreed to a 10 point nationwide agreement on firearms, to be implemented by each Australian state and territory. The Victorian response, the Firearms Act 1996, was implemented on 30 April 1997 (fig 1) and changed existing regulations. Table 1 outlines the details of the 10 point nationwide agreement and the Victorian response.

A national firearm buyback scheme was progressively implemented from September 1996 and ran for 12 months. This was supported by a national firearm amnesty in which people in possession of illegal firearms could hand them in without penalty (fig 1).

This study aimed to describe trends in rates of firearm related deaths in the state of Victoria compared with the rest of Australia for the 22 years between 1979 and 2000 in the context of strong legislative reform to prevent firearm 


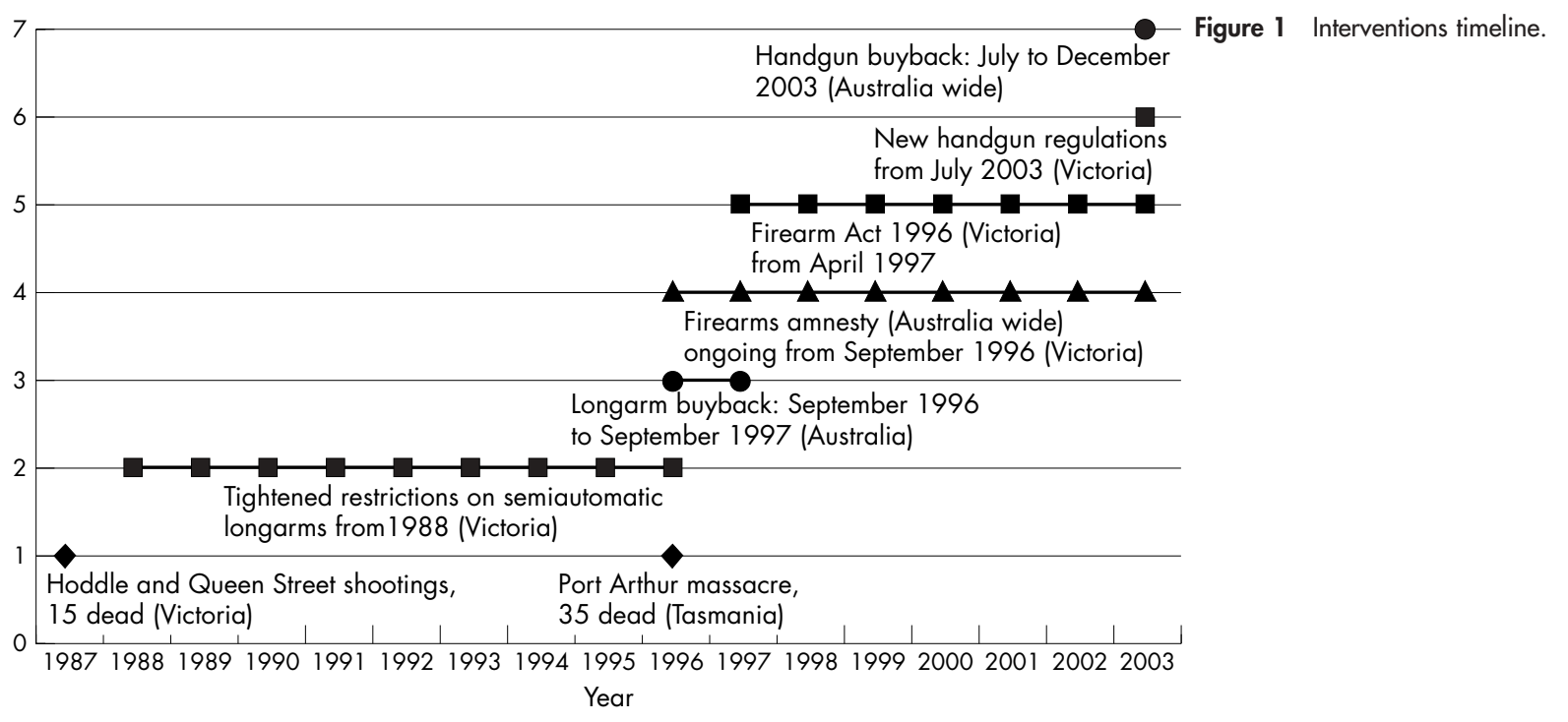

fatalities. It also investigates comparative trends and impact measures to explain the trends.

\section{METHODS}

We used data analysis, literature reviews, and key informant interviews to identify details of death rates, trends, and interventions for control of firearms over the period 19792000 in Victoria and Australia. Victoria, which has a population of 4.2 million, is the second most inhabited Australian state, and Australia has a population of 19.8 million. Victoria's largest city is Melbourne, and $75 \%$ of Victorians reside in metropolitan areas.

We reviewed changes to firearm regulations with government documents, and we obtained population data from the Australian Bureau of Statistics.

We extracted death data, by intent, from the death unit record file of the Australian Bureau of Statistics. Monash University Accident Research Centre holds this data file from 1990-2000; we obtained earlier data from the National Injury Surveillance Unit. We analyzed data on unintentional firearm related deaths (International Classification of Diseases, ninth revision (ICD-9) codes E922.0-E922.9), assaults (E965.0E965.4), suicides (E955.0-E955.4), and deaths of undetermined intent (E985.0-E985.4). The last two years studied use the 10th revision of the ICD (ICD-10), so we mapped data to ICD-9 for comparison.

We calculated rates with population figures derived from estimates by the Australian Bureau of Statistics. We adopted a quasiexperimental design with a Poisson regression model to compare relative rates of firearm related deaths between Victoria and the rest of Australia over three critical periods of legislative reform. These three periods represented prelegislative and post-legislative reforms in Victoria and the rest of Australia: period 1-no legislation (1979-86); period 2: legislation introduced in Victoria (1988-95); and period 3: legislation introduced to the rest of Australia (1997-2000). Data from the rest of Australia acted as the "control" for periods 1 and 2, with the Victorian gun control legislation introduced in period 2. In period 3, the roles of the "treatment" and "control" in the analysis were reversed, with Victoria acting as the control because the gun laws for the rest of Australia came into line with Victoria in period 3. Under this analysis design, we assessed the decrease in the rate of firearm related deaths in Victoria in period 2 relative to Australian trends, as well as the decrease in rates of firearm related deaths in Australia in period 3 relative to
Victorian trends. We compared relative shifts in the rates for Victoria and the rest of Australia with a Poisson regression model that incorporated a fixed offset. We used the death counts as the dependent random variable in the model, while we included an offset (the population counts by region and year) to focus the analysis on rates rather than absolute death counts. Equation 1 shows the form of the model fitted to the annual death counts in Victoria and Australia, where $y$ is the annual death count; $i$ is an indicator for Victoria or the rest of Australia; $j$ is the indicator for year; $v$ is the indicator for period 2 or 3 in Victoria; $a$ is the indicator for period 3 in the rest of Australia; population is the population count for the region and year indexed; and $\alpha, \beta, \delta, \gamma$, and $\phi$ are parameters of the model.

$$
\ln \left(y_{i j v a}\right)=\ln \left(\text { population }_{i j}\right)+\alpha+\beta_{i}+\delta_{j}+\phi_{v}+\lambda_{a}
$$

The indicators in the model take the values $j=1979,1980$, $\ldots, 2002 ; i=0$ for Victoria or 1 for the rest of Australia; $v=1$ if period is 2 or 3 and region is Victoria and 0 otherwise; and $a=1$ if period is 3 and region is Australia and 0 otherwise.

We included the model offset in population levels as a fixed factor, with no associated parameter estimated. Equation 2 gives the net effect of the gun control laws on death rates in Victoria during period 2, relative to Australia, measured as a net percentage reduction in death rate. It measures the change in Victorian death rates from period 1 to period 2, adjusted for corresponding changes in death rates in Australia over the same time period.

$$
\Delta \text { VictoriaPeriod2 }=\left(1-\exp \left(\left(\phi_{1}-\phi_{0}\right)\right)\right) \times 100 \%
$$

In practice, parameterisation of the factors in the model given by equation 1 leaves parameters "aliased." Aliased parameters are those that cannot be estimated because they are a linear product of other parameters in the regression design matrix. Aliased parameters are set to zero in the regression equation. With careful parameterisation and fitting of the model in equation 1 , the parameters $\phi_{0}$ can be aliased. This leads to a reduction in equation 2 to give equation 3. 
Table 1 Details of firearm reform in Australia after the 1996 nationwide agreement and the response in Victoria

\begin{tabular}{ll}
\hline Law requirement for each state and territory & Victorian response to law requirement through \\
according to 10 point nationwide agreement & Firearms Act 1996 and Firearms (Amendment) Act 1998
\end{tabular}

- Ban on importation, ownership, sale, resale, transfer, possession, manufacture, or use of all self loading centre rifles, all self loading and pump action shotguns, and all self loading rimfire rifles (some exemptions allowable to primary producers and clay target shooters)

- Compensatory buyback scheme through which firearm owners would be paid the market value for prohibited firearms handed in during a 12 month amnesty

- Registration of all firearms as part of integrated shooter licensing scheme

- Shooter licensing based on requirement to prove "genuine reason" for owning a firearm, including occupational use, demonstrated membership of an authorized target shooting club, or hunting (with proof of permission from a rural landowner)

- Licensing scheme based on five categories of firearms, minimum age of 18 years, and criteria for a "fit and proper person"

- New licence applicant required to undertake accredited training course in firearm safety

- As well as licence to own a firearm, separate permit required for each purchase of a firearm subject to a 28 day waiting period

- Uniform and strict firearm storage requirements
- Continuation of existing ban in Victoria of semiautomatic long guns and pump action shotguns

- Longarms buyback scheme in Victoria in conjunction with the national buyback scheme from 29 September 1996 to 30 September 1997

- Firearm registration had been required from 1984, so Victoria Police now to keep comprehensive list of all firearms in Victoria

- Several categories of licensing based on new way of categorising firearms (see below for details). Genuine reasons for applying for licence vary with category for firearm:

- Category A or B longarms: sport or target shooting; hunting; primary production; employed as security or prison guard; or accepted official, commercial, or other prescribed purpose

- Category C longarms: primary production; professional hunting; clay target shooting; or official, commercial, or other prescribed purpose. Proof that category A or B firearms would not do required job

- Category D longarms: professional hunting; accepted official, commercial, or other prescribed purpose. Proof that category A, B, or C firearm would not do required job

- Category E: accepted official, commercial, or other prescribed purpose

- Handguns: sport or target shooting; employed as security or prison guard; or official, commercial, or other prescribed purpose

- Adherence to new nationally agreed way of categorizing firearms:

- Category A: airguns, rimfire rifles, shotguns, or any combination of these other than pump action and semiautomatic types

- Category B: muzzle loading firearms, centre fire rifles other than semiautomatic or fully automatic, or any combination of these

- Category C: semiautomatic rimfire rifles with a magazine capacity of no more than 10 rounds, semiautomatic shotguns with a magazine capacity of no more than five rounds, pump action shotguns with a magazine capacity of no more than five rounds, or tranquillizer guns

- Category D: semiautomatic rimfire rifles with a magazine capacity of more than 10 rounds, semiautomatic shotguns with a magazine capacity of more than five rounds, pump action shotguns with a magazine capacity of more than five rounds, or semiautomatic centre fire rifles

- Category E: machine guns, tear gas guns or projectors, shotguns or rifles with a length of less than 75 centimetres parallel to the barrel, cannons, mortars, bazookas, rocket propelled grenades, or similar large calibre military firearms)

- Handguns

- A clear ban on prohibited persons owning or using firearms including a person serving a term of imprisonment for an indictable offence, assault or drug related offence; a 15 year ban, from completion of the prison term, for a person who has served a term of imprisonment of more than 5 years for any of the above offences; a 5 year ban, from completion of the prison term, for a person who has served a term of imprisonment of less than 5 years for any of the above offences; a 5 year ban on persons subject to a domestic violence intervention order in any Australian State or Territory; a 12 month ban against holding a licence for anyone guilty of an offence against the Firearms Act 1996; and a 12 month ban against holding a licence for anyone guilty of an indictable offence

- To own or use longarms or handguns in Victoria, applicants must be able to show they successfully completed a firearms safety training course approved by Victoria Police

- When applying for renewal of a firearms licence, owners required to list all firearms owned

- When new firearm "acquired" (bought, inherited, received as gift, or ownership in any other way), "permit to acquire" application must be obtained from Firearms Registry. A 28 day waiting period applies on permits

- General security requirement: firearms must be carried and used in a manner that is secure and not dangerous, reasonable precautions must be taken against loss or theft, and firearm must not be allowed to be used or carried by person unauthorized to do so 


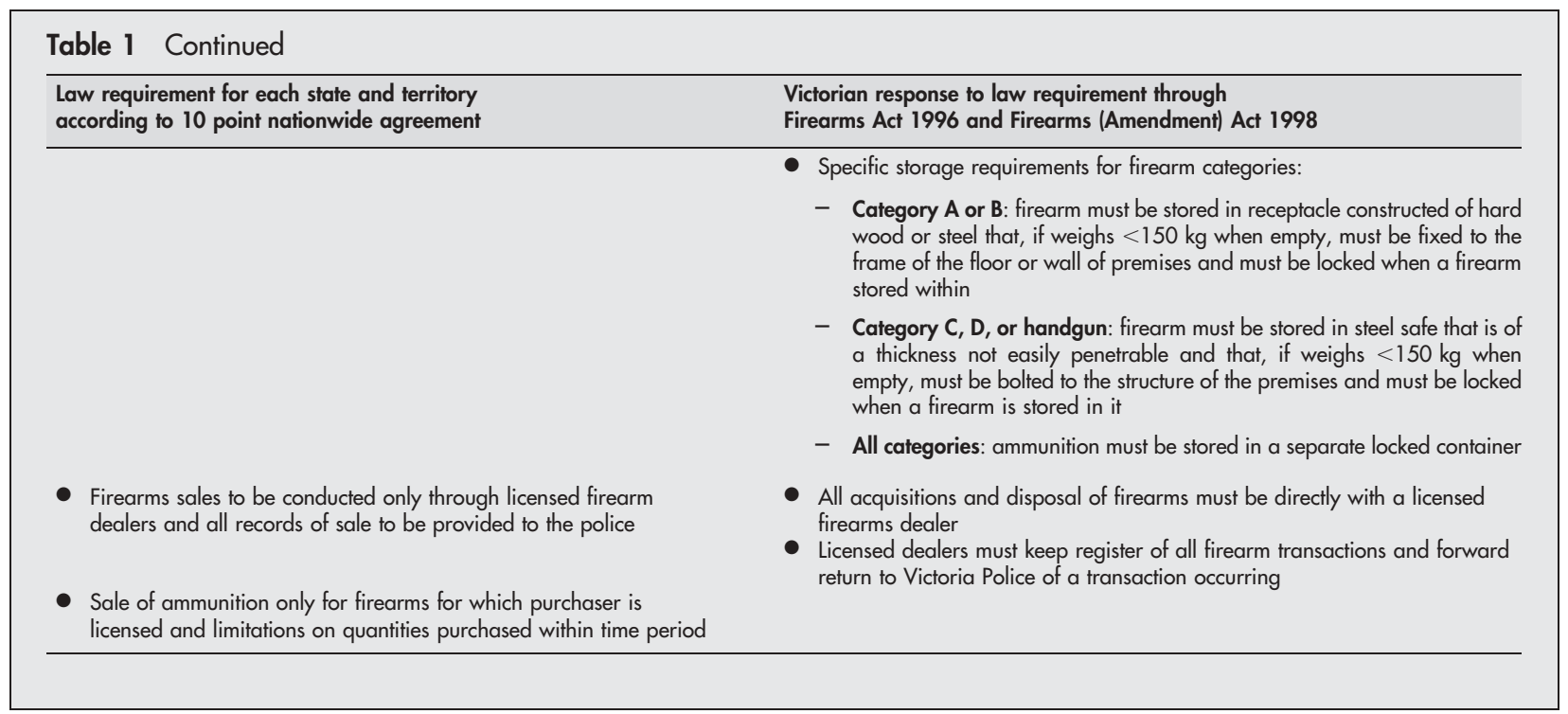

$$
\Delta \text { VictoriaPeriod } 2=\left(1-\exp \left(\phi_{1}\right)\right) \times 100 \%
$$

The form of equation 3 is much more convenient in practice, as statistical testing of the difference in $\mathrm{fl}$ from zero directly tests the significance of the change in death rate in Victoria in period 2 relative to that in Australia. Similarly, the variance of $\phi_{1}$ can be used to compute confidence limits on the estimated change in rate of firearm related deaths.

Similarly, the change in death rate in Australia in period 3, relative to Victoria, is measured by equation 4 .

$$
\Delta \text { AustraliaPeriod } 3=\left(1-\exp \left(\lambda_{1}\right)\right) \times 100 \%
$$

We fitted the Poisson regression model with the Genmod procedure in SAS software (version 8.02). We considered trends to be statistically significant if the $\mathrm{p}$ value of the parameter estimate of the model was less than 0.05 .

As deaths from injuries are not distributed normally, we used the non-parametric equivalent of the paired samples $t$ test, the Wilcoxon signed ranks test, to assess changes in types of injury and deaths caused by firearms (assault, suicide, and unintentional death) for Victoria before and after 1988. All $\mathrm{p}$ values quoted for the Wilcoxon signed ranks test are two tailed, and statistical significance was taken as $\mathrm{p}<0.05$.

Self reported data on firearm ownership for 1992 and 1998 were extracted from surveys by the Australian Bureau of Statistics on hazards and safety features in the home conducted on a representative sample of about 5000 households in Melbourne, Victoria (population 3122971 according to statistics from the 1996 census). Victoria Police provided data on registered firearms and licence holding registered shooters for 1979-2000.

\section{RESULTS}

\section{Firearm related deaths}

Figure 2 shows the trend in rates of firearm related deaths for Victoria and the rest of Australia from 1979 to 2000, with the 1988 and 1996 Victorian legislative changes indicated. The Victorian death rate for firearm related deaths decreased significantly from 4.2 per 100000 in 1979 to 1.5 per 100000 in 2000, which represented an estimated annual percentage change of $-4.9 \%$ (95\% confidence interval -5.9 to -3.9 ) and $64.3 \%$ overall. The death rate for firearm related deaths for the rest of Australian decreased significantly from 5.1 per 100000 in 1979 to 1.8 per 100000 in 2000, which represented an estimated annual percentage change of $-3.9 \%(-4.8$ to -3.1$)$ and an overall reduction of $64.7 \%$.

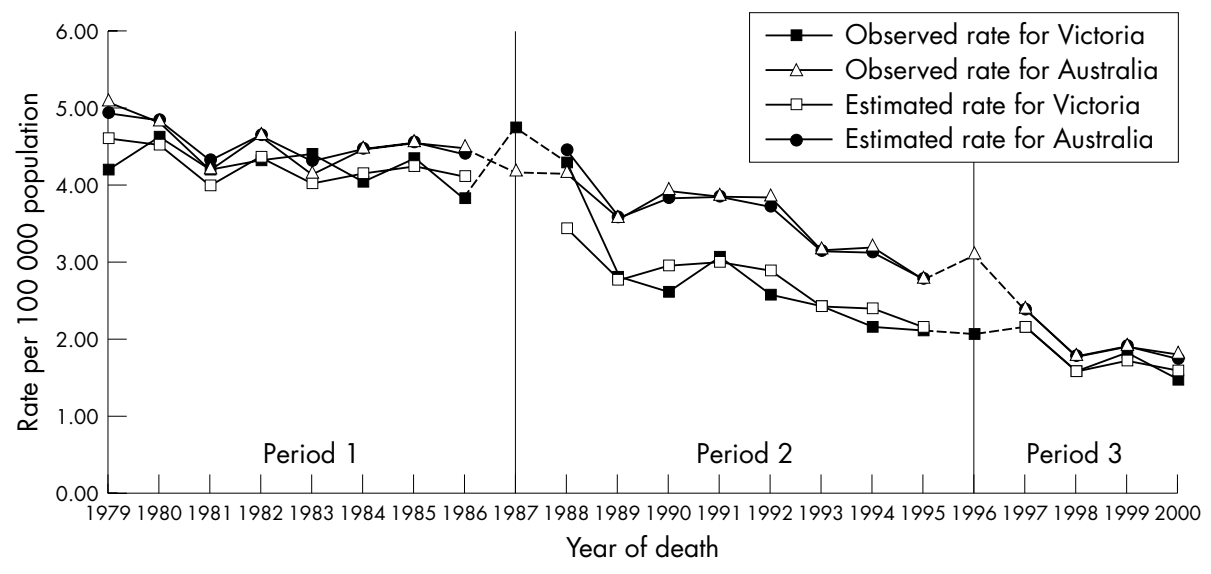

Figure 2 Observed and modelled rates of firearm related deaths in Victoria and the rest of Australia before and after legislative reforms. ${ }^{17}$ Lines show that data from 1987 and 1996 were excluded from these analyses. 
Table 2 Regression model parameter estimates for rates of firearm related deaths for Victoria and rest of Australia for periods 2 and 3

\begin{tabular}{|c|c|c|c|c|c|c|}
\hline \multirow[b]{2}{*}{ Effect } & \multirow[b]{2}{*}{$\begin{array}{l}\text { Parameter } \\
\text { estimate }\end{array}$} & \multicolumn{2}{|c|}{ Estimated reduction } & \multicolumn{3}{|c|}{ Significance test } \\
\hline & & Calculation & $\%$ & $\chi^{2}$ & $\begin{array}{l}\text { Degrees of } \\
\text { freedom }\end{array}$ & p Value \\
\hline $\begin{array}{l}\text { Victoria: period } 2 \\
\text { (1988-95) }\end{array}$ & $\begin{array}{l}-0.1903 \\
\text { (SE } 0.0478 \text { ) }\end{array}$ & $1-\exp (-0.1903)$ & 17.3 & 15.88 & 1 & $<0.0001$ \\
\hline $\begin{array}{l}\text { Australia: period } 3 \\
\text { (1997-2000) }\end{array}$ & $\begin{array}{l}-0.1511 \\
\text { (SE 0.0725) }\end{array}$ & $1-\exp (-0.1511)$ & 14.0 & 4.34 & 1 & 0.0372 \\
\hline
\end{tabular}

The particularly high Victorian rate of 4.9 per 100000 in 1987 corresponds with the Hoddle and Queen Street massacres. The high rate in the rest of Australia in 1996 corresponds with the 35 deaths at Port Arthur in Tasmania. We excluded the 1987 and 1996 massacre years from analysis, as these would make the declines seem more pronounced. Table 2 reports the estimated percentage reduction in death rates associated with the Victorian gun legislation in period 2 and the nationally agreed legislation in period 3, along with statistical significance levels derived from the model.

The Victorian legislation in period 2 was associated with a statistically significant $17.3 \%$ decrease in death rate relative to Australia $(\mathrm{p}<0.0001)$. The Australian (all states and territory) legislation in period 3 was associated with a statistically significant $14.0 \%$ drop in death rate in the rest of Australia relative to Victoria $(p=0.0372)$. Figure 2 shows the fit of the estimated model to the observed data.

A further important analysis outcome was the assessment of the efficacy of the quasiexperimental design. In particular, assessment was needed to determine whether the latent trends in death rates by year were similar in Victoria and the rest of Australia after controlling for the effects of the legislation changes on the series. Similarity in trends indicates each series is a good control for the other. We assessed this by determining the fit of the fitted model by examining the estimated deviance of the model. The model deviance is a $\chi^{2}$ statistic, with low values indicating adequate model fit.

Analysis of the deviance of the model showed the model was an adequate fit to the data $\left(\chi^{2}=24.15\right.$, degrees of freedom $=17, p=0.1154$ ). Consequently, we concluded that the analysis design was valid.

After the 1988 legislative revisions, statistically significant reductions in Victorian frequencies of all firearm related deaths $(p=0.011)$ and firearm related suicides $(p=0.008)$ were seen when we compared the periods 1979-87 and 1988-96. Although decreases were also evident in assaults $(\mathrm{p}=0.108)$ and unintentional firearm related deaths $(\mathrm{p}=0.05)$ over this same time period, they did not reach statistical significance (table 3 ). Further declines in overall firearm related deaths and firearm related suicides and assaults followed the additional legislative reforms in 1996. Unintentional firearm related deaths increased slightly during 1997-2000 in Victoria. The annual average frequency is low, however, and therefore prone to fluctuation. The reduction in annual frequency for suicide accounted for $78 \%$ of the total reduction in annual average frequency of firearm related deaths over this period.

\section{Firearm ownership}

Representative household surveys in Melbourne, Victoria, undertaken by the Australian Bureau of Statistics in 1992 and 1998, show that the number of households that reported firearm and ammunition possession decreased in Melbourne over this period. The 1992 survey found that $7.4 \%$ of all households and $8.3 \%$ of households with children aged $<5$ years kept a firearm on the property and that $5.2 \%$ of all households and $5.6 \%$ of households with children aged $<5$ years kept ammunition. The repeat survey found reductions in all categories. In the 1998 survey, 4.4\% of all households and $3.5 \%$ of households with children aged $<5$ years kept a firearm on the property and $3.1 \%$ of all households and $2.5 \%$ of households with children aged $<5$ years kept ammunition.

Data from the Victoria Police firearm registry show that the numbers of registered firearms and current licence holding registered shooters in Victoria declined during the four years between 1997-98 and 2000-01 (fig 3). These figures equate to a $25 \%$ reduction in registered firearms and $15 \%$ reduction in licences over the four years.

The National Firearms Buyback Scheme and associated publicity operated for 12 months from September 1996 ( fig 1). Over this period, 660959 firearms were collected and destroyed nationwide, with a total compensation cost of

Table 3 Firearm related deaths in Victoria by intent before and after legislative reform in periods 1 (1979-87), 2 (1988-96), and 3 (1997-2000)

\begin{tabular}{|c|c|c|c|c|}
\hline \multirow[b]{2}{*}{ Period } & \multicolumn{4}{|l|}{ Intent } \\
\hline & Suicide & Assault & Unintentional & Total $^{*}$ \\
\hline \multicolumn{5}{|c|}{ Average annual frequency of deaths (period total frequency) } \\
\hline 1 & $132.5(1193)$ & $29.0(261)$ & $7.7(69)$ & $174.1(1567)$ \\
\hline 2 & $90.5(815)$ & 20.4 (184) & $4.1(37)$ & $118.1(1063)$ \\
\hline 3 & $60.3(241)$ & $14.5(58)$ & $6.0(24)$ & $82.0(328)$ \\
\hline \multicolumn{5}{|c|}{ Change in average annual frequency between different periods } \\
\hline 1 and 2 & -42 & -8.6 & -3.6 & -56 \\
\hline 2 and 3 & -30.2 & -5.9 & +1.9 & -36.1 \\
\hline 1 and 3 & -72.2 & -14.5 & -1.7 & -92.1 \\
\hline \multicolumn{5}{|c|}{ Change between different periods (\%) } \\
\hline 1 and 2 & -31.7 & -29.7 & -46.8 & -32.2 \\
\hline 2 and 3 & -33.4 & -28.9 & +46.3 & -30.6 \\
\hline 1 and 3 & -54.5 & -50.0 & -22.1 & -52.9 \\
\hline
\end{tabular}




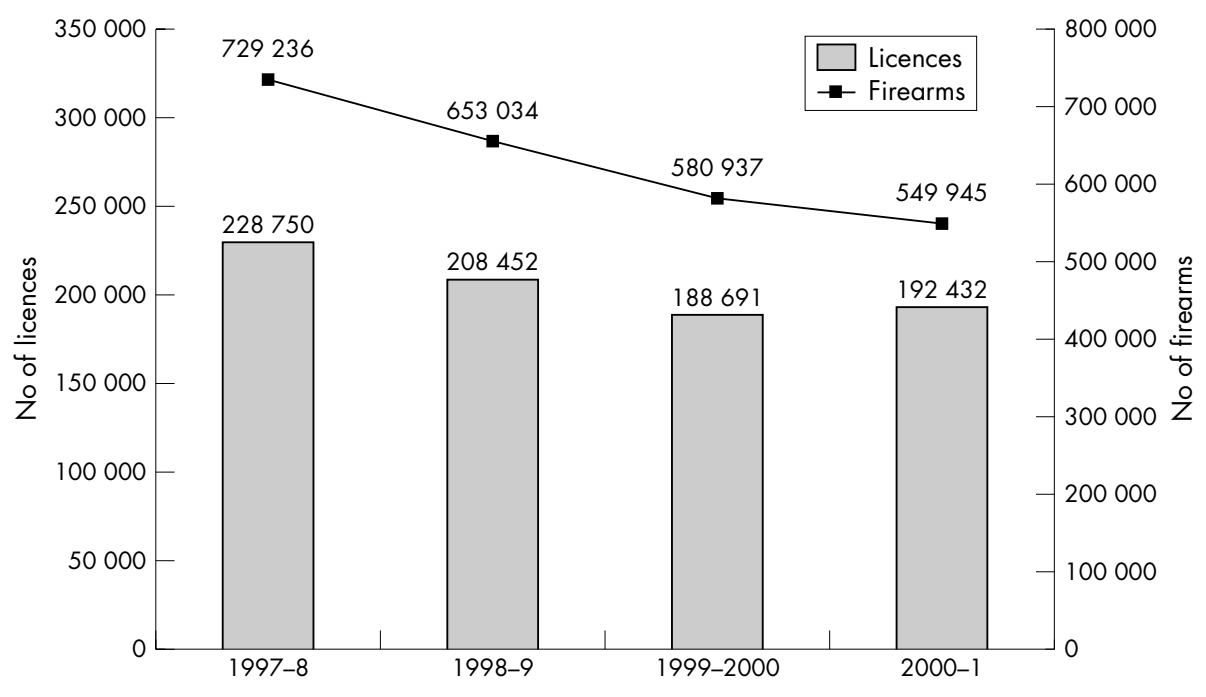

Figure 3 Gun owner licences and registered firearms in Victoria. ${ }^{18}$

almost \$A394 million (\$176m). Some 207409 of the collected firearms were from Victoria. ${ }^{19}$

\section{DISCUSSION}

This study shows dramatic declines in rates of firearm related deaths in the state of Victoria, and for the rest of Australia, for the 22 years between 1979 and 2000 in the context of strong legislative reform. Earlier legislative reform in Victoria, compared with the rest of Australia, was associated with more rapid initial declines. Evidence for this relation is strengthened by the differential rates associated with the tightening of regulations earlier in Victoria (in 1988) compared with the remainder of Australia and the ultimate "catch up" by the rest of Australia after regulation was introduced in the other states. Declines in household ownership of firearms, firearm licences, and licenced shooters in Victoria and the national firearms buyback scheme (from 1996) were associated with these trends. These changes were associated with substantial publicity, unprecedented community awareness, and advocacy for gun control reform from antigun groups and the broader community. ${ }^{16}$

In particular, our data analysis shows significant reductions in firearm related suicides and assaults after both periods of reform in Victoria. Studies that focused only on suicide in the states of Queensland and South Australia support our findings. ${ }^{20} 21$ Similarly, two international studies by Rich et al and Loftin et al, which examined the effects of strengthened firearm laws in Ontario and Washington, DC in

\section{Key points}

- Significant and dramatic declines in rates of firearm related deaths occurred in Victoria and Australia after periods of strong legislative reform.

- Statistically significant reductions in firearm related suicides were observed after legislative reforms.

- In 2000, rates of firearm related deaths were less than two per 100000 population for Victoria and Australia compared with 10.4 per 100000 population for the United States.

- In Victoria, reductions in the numbers of registered firearms of $25 \%$ and of licensed shooters of $15 \%$ were seen over the four years between 1997-98 and 2000-01. the United States, respectively, reported decreases in firearm related suicides. ${ }^{22}{ }^{23}$

Supportive evidence for the relation between firearm ownership and prevalence of fatalities also comes from a number of American studies. Miller et al, in a pooled cross sectional time series analysis over 10 years (1988-97), found that a disproportionately high number of children aged 5-14 years died from suicide, homicide, and unintentional firearm related deaths in American states and regions in which firearms were more prevalent. ${ }^{6}$ Kellermann et al conducted case-control studies to examine the links between firearm ownership as a risk factor for suicide and homicide in the home. $^{10}{ }^{12}$ After controlling for several factors, they found that the presence of one or more firearms in the home was associated with an increased risk of suicide (adjusted odds ratio $4.8,95 \%$ confidence interval 2.7 to 8.5$).{ }^{10}$ Similarly, keeping a firearm in the home was strongly and independently associated with an increased risk of homicide (adjusted odds ratio $2.7,1.6$ to 4.4 ). ${ }^{12}$

The methods used in this study were capable of showing a strong association between firearm regulations and the significant decline in firearm related fatalities. This relation was further supported by impact measures. Further evidence would be needed to show that the relation is causal. For reasons associated with coding systems, this study was unable to consider type of firearm.

For the same period, despite the declines related to firearms, overall suicide and homicide rates in Victoria did not show a similar decline. An analysis of substitution or displacement to other methods of suicide or homicide was beyond the scope of this study. Investigation of the rates of non-fatal firearm related injury was also out of the scope of this study.

The very low rate of fatalities from firearms achieved in Australia by the year 2000 ( $<2$ per 100000 population) raises the question of whether vision zero (elimination of firearm related fatalities) is achievable. In the course of this research, our own institution-Monash University-was the site of a shooting that resulted in the death of two members of our community. In the aftermath of the events at Monash, the Australian, state, and territory governments made a National Handgun Control Agreement. This agreement aims to reduce the number of handguns held in the community, particularly concealable handguns, and to strengthen control over access to handguns. ${ }^{24}$ The Firearms (Trafficking and Handgun Control) Act 2003 started in Victoria on I July 2003 with a supporting amnesty and buyback scheme to run until 31 December 2003. The impact of this further reform will be monitored. 


\section{CONCLUSION}

Dramatic reductions in overall firearm related deaths and particularly suicides by firearms are achievable in the context of the implementation of strong regulatory reform.

\section{ACKNOWLEDGEMENTS}

This research was funded by the Victorian Department of Human Services, Victorian Health Promotion Foundation, and Monash University Accident Research Centre Strategic Development Program.

Information and support were provided by Superintendent David Dettman and Martin Stewart (Victoria Police), Wendy Cukier (Ryerson University, Toronto, Canada), and Margaret Trotter (Injury Prevention and Research Unit, University of Otago, New Zealand).

\section{Authors' affiliations}

J Ozanne-Smith, K Ashby, S Newstead, V Z Stathakis, A Clapperton, Monash University Accident Research Centre, Monash University,

Victoria, Australia

\section{REFERENCES}

1 Alpers P. Yes, Americans are often shot-and so are many others. Inj Prev 2002;8:262.

2 Minino AM, Arias E, Kochanek KD, et al. Deaths: final data for 2000. Nat Vital Stat Rep 2002;50:1-119.

3 Centers for Disease Control. Nonfatal and fatal firearm-related injuriesUnited States, 1993-1997. MMWR Morb Mortal Wkly Rep 1999:48:1029-34.

4 Culross $P$. Legislative strategies to address firearm violence and injury. J Fam Pract 1996;42:15-7.

5 Romero MP, Wintemute GJ. The epidemiology of firearm suicide in the United States. J Urban Health 2002;79:39-48.

6 Miller M, Azrael D, Hemenway D. Firearm availability and unintentional firearm deaths, suicide and homicide among 5-14 year olds. J Trauma 2002;52:267-75.
7 Killias M, van Kesteren J, Rindlisbacher M. Guns, violent crime, and suicide in 21 countries. Can J Criminol 2001;43:429-48.

8 Dudley M, Cantor C, de Moore G. Jumping the gun: firearms and the mental health of Australians. Aust N Z J Psychiatry 1996;30:370-81.

9 Brent DA, Perper JA, Moritz G, et al. Firearms and adolescent suicide: a community case control study. Am J Dis Child 1993;147:1066-71.

10 Kellermann AL, Rivara FP, Somes G, et al. Suicide in the home in relation to gun ownership. N Engl J Med 1992;327:467-72.

11 Brent DA, Perper JA, Allman CJ, et al. The presence and accessibility of firearms in the homes of adolescent suicides-a case control study. JAMA 1991;266:2989-95.

12 Kellermann AL, Rivara FP, Rushforth NB, et al. Gun ownership as a risk factor for homicide in the home. N Engl J Med 1993;329:1084-91.

13 Gabor T, Roberts JV, Stein K, et al. Unintentional firearms deaths: can they be reduced by lowering gun ownership levels? Can J Public Health 2001;92:396-8.

14 Hung K. Firearm statistics - updated tables. Ottawa: Department of Justice, 2003.

15 Injury Prevention Research Service. Data supplied by the Injury Prevention Research Service, University of Otago, New Zealand, May 2004.

16 Chapman S. Over our dead bodies: Port Arthur and Australia's fight for gun control. Sydney: Pluto Press, 1998.

17 Australia Bureau of Statistics. Causes of death Australia. Cat 3303.0. Unpublished data available on request. Canberra: Australian Bureau of Statistics.

18 Victoria Police. Victoria Police "LARS" System. Melbourne: Database held by Licensing Services Branch, Victoria Police (data accessed 2002).

19 Attorney General's Department. Data supplied by the Firearms Unit, National Law Enforcement Policy Branch, Criminal Justice Division, September 2004.

20 Cantor $\mathrm{CH}$, Slater PJ. The impact of firearm control legislation on suicide in Queensland: preliminary findings. Med J Aust 1995;162:583-5.

21 Snowdon J, Harris L. Firearms suicides in Australia. Med J Aust 1992;156:79-83.

22 Rich CL, Young JG, Fowler RC, et al. Guns and suicide: possible effects of some specific legislation. Am J Psychiatry 1990;147:342-6.

23 Loftin C, McDowell D, Wiersema B, et al. Effects of restrictive licensing of handguns on homicide and suicide in the District of Colombia. N Engl J Med 1991;325:1615-20.

24 Victoria Police. The Victorian handgun buy-back. Victoria: Victoria Police, 2003. Available at: http://www.police.vic.gov.au/handgunbuyback/ amnesty.htm. 